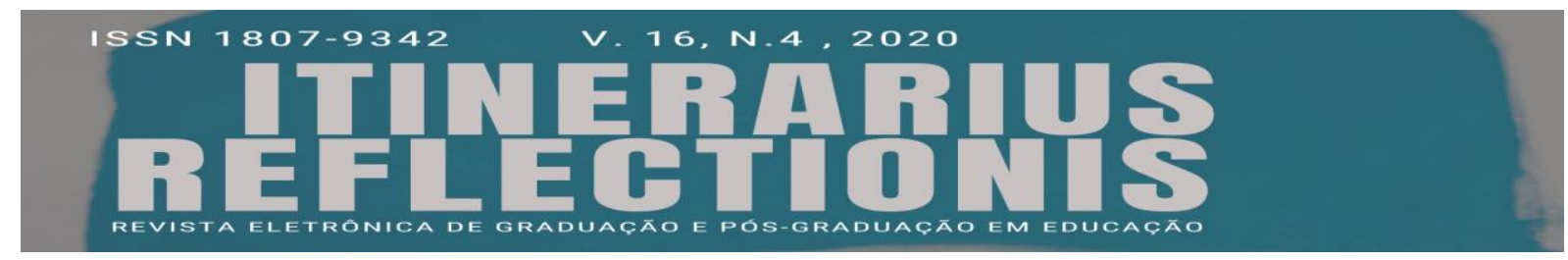

\title{
Considerações sobre a formação clínica do estudante no serviço de psicologia aplicada (SPA)
}

\author{
André Roveda ${ }^{1}$ \\ Nilton Cesar Barbosa ${ }^{2}$
}

\section{Resumo}

Este artigo tem como objetivo tecer algumas considerações teóricas e experienciais sobre a formação clínica de estagiários de Psicologia a partir dos pressupostos da terapia centrada no cliente dentro do Serviço de Psicologia Aplicada (SPA). Inicialmente, descreve-se o terapeuta, suas características pessoais e profissionais e a influência dessas no processo terapêutico. Além disso, pondera-se sobre a supervisão e seus pressupostos essenciais e apresenta-se a versão de sentido como uma estratégia potencialmente enriquecedora para a formação durante a prática supervisionada. São feitas algumas considerações sobre o Serviço de Psicologia Aplicada, tendo em vista as orientações para a formação contidas nas Diretrizes Curriculares Nacionais (DCN) e as críticas em relação à prática clínica tradicional. Em seguida, faz-se um relato da experiência das práticas de estágio e extensão realizadas no SPA como parte da formação do psicólogo. Destaca-se as contribuições da relação na valorização do humano e na formação profissional, tanto na experiência vivenciada durante as supervisões quanto nas sessões com os clientes e com os demais profissionais que compartilham o SPA. Conclui-se que a formação clínica proporciona as condições para que o psicólogo tenha uma postura que valoriza o potencial humano para lidar com os desafios e conflitos inerentes às relações, de maneira crítica e reflexiva. Dentre os desafios ainda por serem superados, destaca-se a valorização institucional do Serviço de Psicologia; a construção de um espaço físico específico e adequado às necessidades dos usuários; a necessidade de ampliar o diálogo entre as diferentes abordagens teóricas e a aproximação das práticas realizadas no Serviço de Psicologia Aplicada, o que poderá fomentar uma visão mais plural e generalista do papel do psicólogo e da sua atuação em meio às questões sociais contemporâneas.

Palavras chave: Terapia centrada no cliente. Supervisão. Versões de sentido.

\section{Considerations about the student's clinical training in the applied psychology service (APS)}

\begin{abstract}
This article aims to make some theoretical and experiential considerations about the clinical training of Psychology interns from the assumptions of client-centered therapy within the Applied Psychology Service (APS). Initially, the therapist is described, his personal and professional characteristics and their influence on the therapeutic process. In addition, ponders about to supervision and its essential assumptions and the version of meaning is presented as an potentially enriching strategy for training during supervised practice. Some considerations are made about the Applied Psychology Service, in view of the guidelines for training contained in the National Curriculum Guidelines (NCG) and the criticisms in relation to traditional clinical practice. Then, a report is made of the experience of the internship and extension practices performed at the APS as part of the training of the psychologist. The contributions of the relation in the valorization of the human and professional training are highlighted, both in the experience lived during the supervision and in the sessions with the clients and

\footnotetext{
${ }^{1}$ Graduando em Psicologia pela UFJ. Universidade Federal de Jataí/UFJ. Jataí-GO, andreroveda$97 @$ hotmail.com.

${ }^{2}$ Doutor em Psicologia pela PUC-Campinas. Universidade Federal de Jataí/UFJ. Jataí-GO. nilton_cesar_barbosa@ufg.br.
} 
with the other professionals who share the APS. It is concluded that clinical training provides the conditions for the psychologist to have a posture that values human potential to deal with the challenges and conflicts inherent in relationships, in a critical and reflective way. Among the challenges yet to be overcome, the institutional valorization of the Psychology Service stands out; the construction of a specific physical space suitable to the needs of users; the need to expand the dialogue between the different theoretical approaches and the approximation of the practices carried out in the Applied Psychology Service, which may foster a more plural and generalist view of the role of the psychologist and his performance in the midst of contemporary social issues.

Keywords: Client-centered therapy. Supervision. Sense's version.

\section{FUNDAMENTAÇÃO TEÓRICA}

Ao longo da vasta produção intelectual de Carl Rogers (SHARF, 2012), observase que os pressupostos teóricos que embasaram a Terapia Centrada no Cliente (ROGERS, 1992) também influenciaram sua crença em uma sociedade capaz de promover relações interpessoais voltadas para o crescimento e o desenvolvimento pessoal. Esta sociedade vislumbrada por Rogers seria capaz de valorizar as relações a partir de atitudes como a empatia, a autenticidade e a aceitação positiva (SCHMIDT, 2011).

Assim, os pressupostos da Terapia Centrada no Cliente foram além do espaço da clínica e promoveram a criação de um movimento que se espalhou pelo mundo e influenciou profissionais de diferentes áreas do conhecimento (KIRSCHENBAUM; JOURDAN 2005). O grande interesse e envolvimento das pessoas com suas ideias levaram Rogers a acreditar no potencial para o crescimento pessoal e a autocompreensão não só daqueles indivíduos submetidos à terapia, mas de todas as pessoas. Para Schmidt (2011) essa perspectiva tornouse efetivamente libertária a partir da ênfase nas atitudes facilitadoras. Essas atitudes contribuiriam para a pessoa se tornar mais consciente de suas formas de significação e capacidade para lidar com os conflitos e desafios oriundos das relações interpessoais e das estruturas sociais vigentes.

A concepção de homem que fundamenta a Terapia Centrada no Cliente se baseia em algumas crenças que são compartilhadas por todos aqueles que praticam as várias formas de terapias centradas na pessoa. Dentre elas se destacam: a natureza humana é basicamente construtiva e social; as percepções individuais são o principal determinante da experiência e do comportamento pessoal e, por isso, para entender uma pessoa é preciso buscar entende-la empaticamente; as pessoas se percebem e se protegem da melhor forma possível, a partir das condições internas e externas presentes naquele momento; abdicação do controle e do 
exercício de autoridade sobre outras pessoas; promover relações baseadas no compartilhamento de decisões e responsabilidades, dentre outras (BRODLEY, 2019).

\subsection{O terapeuta na perspectiva da terapia centrada no cliente}

O terapeuta centrado no cliente se empenha em criar condições relacionais para que o cliente se sinta suficientemente seguro para entrar em contato com suas experiências emocionais mais profundas, muitas vezes difíceis de serem reconhecidas como parte de si mesmo. Para isso, na terapia centrada no cliente a relação entre terapeuta e cliente ocorre de maneira horizontal, ou seja, o terapeuta se coloca em uma posição igualitária, sem se pautar na necessidade de demonstrar mais conhecimento ou experiência do vivido. O terapeuta busca reconhecer na experiência narrada pelo cliente uma vivência única, genuína e tão real quanto tudo o que pode ser vivido no momento (ROGERS; KINGET, 1977).

Desta maneira, o terapeuta procura assumir atitudes de aceitação positiva incondicional, compreensão empática e autenticidade ao longo da relação terapêutica, orientado por uma confiança genuína na capacidade de autorrealização da pessoa (FREIRE E TAMBARA, 2000). Ao promover um ambiente em que essas atitudes são expressas, o terapeuta cria as condições para uma crescente autonomia do cliente em relação ao processo terapêutico (ROGERS, 1992).

A atitude de aceitação dos diferentes aspectos das experiências vividas e relatadas pelo cliente promove, gradativamente, uma disposição interna do cliente para entrar em contato com os vários componentes dessa experiência. Com isso, o cliente pode reconhecer as várias partes da sua realidade psíquica como sendo parte do próprio self e, aos poucos, aceitar este self mais complexo como sendo tudo o que é possível ser (SILVA; AMARAL; RODRIGUES 2018).

A atitude de compreensão empática envolve a disponibilidade do terapeuta em ouvir e procurar captar o que o paciente está sentindo, os significados pessoais para as experiências vivenciadas ao longo da sessão e comunicar sua percepção em relação ao que está experienciando no momento. Como a percepção do terapeuta envolve sua perspectiva pessoal e emocional sobre o que o paciente está expressando, ele procura compartilhar suas impressões a partir de uma possibilidade. O terapeuta então destaca que sua fala expressa sua experiência e indaga se esta percepção reflete ou representa aquilo que está sendo vivido pelo 
cliente (ROGERS; KINGET, 1977; ROGERS, 1983). Esta atenção constante, interessada e genuína, promove uma sensação de estar sendo ouvido, de que esta pessoa que está diante do cliente realmente se interessa pelos seus sentimentos e suas experiências.

Quando o cliente escuta o terapeuta descrever o que ouviu de forma empática, clara e objetiva, ele tem a oportunidade de olhar para sua vida e suas experiências de outra maneira. Isso, no início, incomoda e gera mais desconforto, pois, o cliente se vê diante de comportamentos e de um jeito de ser que ele não concorda ou não reconhece como sendo ele mesmo. Porém, ao longo do processo, o cliente experiencia condições que reconhecem e aceitam seu incomodo em ser quem não gostaria de ser. Gradativamente, ele percebe que suas mais diferentes experiências são reconhecidas como legítimas e importantes e, isso contribui para que também passe a valorizá-las e aceitá-las como parte do próprio self (ROGERS, 1992; 2008).

Além disso, o terapeuta busca expressar uma atitude de autenticidade em relação ao que percebe e sente sobre o cliente. Esta atitude implica em assumir os próprios sentimentos na relação, ainda que pareçam inicialmente negativos. A expressão dos sentimentos presentes promove uma aproximação maior entre terapeuta e cliente, na medida em que revela a fragilidade e a humanidade do terapeuta. Isso também colabora para criar um clima favorável no qual o cliente se sente mais seguro ao experienciar seus sentimentos como parte inerente do self. Durante a relação, ele pode fazer isso sem negar ou tentar selecionar aquilo que parece ser mais adequado socialmente ou aceitável, do ponto de vista das crenças e valores internalizados (SILVA; AMARAL; RODRIGUES 2018; ROGERS, 2008).

O cliente experimenta a sensação de segurança em relação ao terapeuta na medida em que qualquer sentimento ou atitude descrita é aceita e reconhecida como legítima e importante. Ao longo das sessões, a experiência de se deparar com aspectos seus que ele não reconhecia ou não aceitava vai se tornando mais frequente e menos assustadora, na medida em que ele vê no terapeuta essa postura calorosa e acolhedora de tudo o que ele é. Assim, aos poucos, passa a experienciar cada vez menos culpa diante dos seus sentimentos, tanto os socialmente aceitos quanto aqueles hostis e antes condenáveis. Com isso, ele vai se tornando cada vez mais capaz de conviver com todas essas variações que o compõem, independente do caráter positivo ou negativo que elas evocam (ROGERS, 1992). 


\subsection{A supervisão}

A supervisão oferecida ao longo dos estágios é parte essencial da formação teórica e prática do estudante de Psicologia. Neste período da formação, o estágio se torna uma oportunidade de estabelecer novas relações, constituir uma identidade profissional e desenvolver habilidades e competências específicas do psicólogo (MONTEIRO; NUNES, 2008). Essa fase envolve dúvidas e insegurança diante dos desafios da prática. Nesse sentido, a supervisão se torna um momento em que o estudante recebe suporte teórico e emocional para lidar tanto com as demandas do cliente quanto com os seus próprios sentimentos (TAVORA, 2002).

Tendo como base a terapia centrada no cliente, Patterson (2000) se refere à supervisão como um espaço que enfatiza mais as atitudes facilitadoras do que o desenvolvimento de habilidades. Sugere, para o exercício das atitudes, três regras básicas: 1) ênfase na escuta, ou seja, para realmente ouvir o cliente, o terapeuta busca centrar-se no que está sendo dito; 2) Evitar perguntas, a menos que realmente não consiga entender o que foi dito e 3) Ser responsivo, no sentido de permitir que o cliente escolha o que vai dizer e seguir este caminho com ele.

No início do processo de supervisão, o supervisor deve informar quais os critérios que serão utilizados para avaliação dos terapeutas. Os critérios envolvem o estudante ser capaz de criar as condições necessárias para a mudança terapêutica a partir da expressão de atitudes facilitadoras ao longo da relação com o cliente (PATTERSON, 2000).

De acordo com Buys (1987) o processo de supervisão pode ser estruturado em três fases ou períodos. Inicia-se a supervisão com a preparação teórica e técnica centrada no terapeuta iniciante. Neste momento o supervisor procura relacionar o conhecimento com as experiências vivenciadas pelo terapeuta a fim de que ele possa experienciar as atitudes facilitadoras em si mesmo e na relação. Em um segundo momento o supervisor promove condições para que o terapeuta encontre significados para as experiências vividas, se apropriando do conhecimento e das atitudes facilitadoras. Por fim, o supervisor estimula a busca por um jeito de ser terapeuta, valorizando as características individuais e a abertura para a auto realização.

A supervisão promove o acesso ao conhecimento teórico e técnico, além de um momento experiencial, quando o terapeuta é estimulado a entrar em contato consigo mesmo, 
com a relação que estabelece com o cliente e com o supervisor (TAVORA, 2002). Assim, ainda que o processo de formação dê ênfase na experiência relacional como aspecto essencial para o desenvolvimento das atitudes facilitadoras, é fundamental que o terapeuta tenha conhecimento e domínio teórico da abordagem e da produção científica na área (ROGERS, 1992; BORIS, 2008).

Vieira, et al. (2018) também ressaltam a importância do domínio do conhecimento teórico e das pesquisas científicas realizadas na área. Além disso, destacam que a formação do terapeuta envolve dois aspectos que parecem inicialmente distantes, mas que acabam por se influenciarem mutuamente. De um lado existe a necessidade do exercício das atitudes facilitadoras e do outro a crença de que a experiência pode promover uma aprendizagem mais significativa e uma sensibilidade maior sobre as relações humanas. Neste sentido, a supervisão, de preferência em grupo, torna-se um espaço para viver a experiência e reviver a relação com o cliente. Assim, torna-se possível entrar em contato com aspectos de si e do outro que podem suscitar novos significados e formas diferentes de compreensão da relação e do próprio terapeuta.

Dito de outra maneira, a supervisão é facilitadora do processo de tornar-se terapeuta. É onde trata-se de situações vividas em atendimentos como experiência potencialmente transformadora da maneira como o terapeuta iniciante percebe a relação e a si mesmo.

Assim, a supervisão dá mais ênfase no desenvolvimento das habilidades terapêuticas do que nas experiências individuais do cliente. Isso ocorre porque o foco da supervisão está centrado no terapeuta e no material que foi filtrado por sua percepção. A experiência do cliente está sempre presente na supervisão, porém, para contribuir com a formação e a relação terapêutica, o supervisor centra na experiência vivida pelo terapeuta. Ele atua desta maneira porque reconhece que essa experiência está carregada de sensações e sentimentos, muitas vezes não percebidos pelo terapeuta iniciante e envolve elementos importantes para promover o reconhecimento e a aceitação de tudo o que se é (TALLEY; JONES, 2019).

O supervisor ajuda o terapeuta iniciante no processo de adentrar o universo singular do cliente e compartilhar a experiência vivida. Aos poucos, o terapeuta vai reconhecendo a importância de compartilhar a experiência e de se desvencilhar deste 
emaranhado emocional, deixando esse mundo complexo sem levar consigo parte da experiência que é do cliente e não de si mesmo (ROGERS, 1992).

Durante a supervisão, o objetivo do supervisor é criar um clima favorável para que o terapeuta experiencie tudo o que o cliente desencadeou emocionalmente nele e possa explorar os significados relacionados a essa experiência. Esse ambiente acolhedor é promovido a partir da expressão das atitudes facilitadoras pelo supervisor. Ele se relaciona buscando aceitar a realidade psíquica do terapeuta, de forma empática e autêntica. Com isso, o terapeuta pode perceber que foi empático o suficiente para compartilhar as mesmas sensações de medo, ansiedade, angústia, entre outras que o cliente compartilhou ao longo da sessão (SILVA, 2006).

Ao lidar com os significados trazidos pelo terapeuta, o supervisor oferece suporte para que ele se aproxime deste sentir através da aceitação incondicional da experiência e de uma compreensão empática e autêntica em relação aos sentimentos compartilhados durante a supervisão. Esse momento é importante para que o estudante vá se tornando mais consciente de seus próprios estados emocionas e de como eles afetam a sua atuação terapêutica. Além disso ele tem a oportunidade de experienciar o fazer terapêutico na supervisão e pode usar sua própria vivência como parâmetro para a relação com o cliente. Ele reconhece os efeitos terapêuticos das atitudes facilitadoras no cliente ao se permitir vivenciar os próprios sentimentos. Desta maneira, ele vai valorizando cada vez mais a empatia e a autenticidade na relação, além dos efeitos terapêuticos de uma atitude de aceitação positiva do seu jeito de ser e do jeito de ser do cliente (ROGERS, 1983; TAVORA, 2002, OLIVEIRA, 2014).

Além de criar um clima caloroso e propício para experienciar as atitudes facilitadoras, o supervisor também tem como objetivo que o estagiário desenvolva um senso avaliativo interno, reflita sobre como conduziu a sessão e identifique como sua forma de sentir e expressar o conteúdo relatado afeta a relação. Esta autoconsciência colabora para que o estagiário vá aos poucos reconhecendo sua capacidade de promover as condições para a mudança, bem como suas dificuldades para lidar com o outro, de forma que pode usar isso na relação terapêutica e em seu crescimento pessoal (PATTERSON, 2000).

O supervisor busca valorizar cada estagiário enquanto ser único, aceitando a complexidade das experiências e dos sentimentos que marcam e diferenciam cada pessoa (TALLEY; JONES 2019). Isso significa que ele atua constantemente para que o estagiário 
possa se tornar o terapeuta que pode ser e não uma réplica distorcida do supervisor. O que se busca é oferecer apoio para que o estagiário desenvolva seu próprio estilo de ser terapeuta e aprenda a respeitar o fato de que cada pessoa se envolve na relação da melhor maneira que pode no momento presente.

O estagiário pode fazer uso da relação com o supervisor para entrar em contato com questões terapêuticas da mesma maneira que o cliente pode fazer uso do relacionamento terapêutico para entrar em contato com suas questões pessoais. Assim, as condições de autenticidade, empatia e aceitação estão presentes na supervisão de forma muito semelhante àquela que o terapeuta busca expressar durante a sessão (VIEIRA, et al., 2018).

\subsection{A versão de sentido como uma ferramenta de supervisão}

A versão de sentido se caracteriza como um relato escrito da experiência vivenciada pelo terapeuta ao longo da sessão. Diferente de um relato objetivo da sessão, a versão de sentido baseia-se em uma livre descrição do que emerge espontaneamente sobre o encontro, incluindo as impressões sobre o cliente e sobre si mesmo (BORIS, 2008).

A versão de sentido enquanto registro feito logo após a conclusão da sessão enfatiza os sentimentos vivenciados pelo terapeuta durante a relação. É um relato da experiência mais complexa e profunda daquilo que foi vivido pelo terapeuta e, por isso contêm uma vasta quantidade de material experiencial para ser explorado na supervisão (BORIS, 2008).

Segundo Amatuzzi (2019), a versão de sentido permite um olhar de síntese mais imediato e rápido do que o que é possível obter através de horas de entrevistas gravadas (p. 101). Ao elaborar seu relato, o estudante recupera significados experienciados durante e após o atendimento. Esses significados podem então ser compartilhados com o supervisor e o grupo de maneira viva e envolvente (VIEIRA et al., 2018).

Além disso, é possível utilizar as versões de sentido produzidas pelos estagiários, considerando a experiência grupal de formação e a relação estabelecida com o supervisor. Isso ocorre porque os significados que emergem durante o encontro do grupo são compostos do mesmo material que emerge durante os atendimentos. Desta maneira, o que é vivido ao longo dos encontros de supervisão acaba sendo uma experiência preparatória para o que irá ocorrer nos atendimentos. A supervisão se torna assim, não só espaço de orientação técnica, 
mas um espaço vivencial, um momento de treinamento para o atendimento (PATTERSON, 2000).

Interessa ao supervisor os significados que emergem do relato. Comumente, a versão de sentido foca em um ou outro aspecto em meio a tudo o que ocorreu ao longo da sessão. Essa seleção subjetiva e os significados que a acompanham são utilizados pelo supervisor para levar o estudante a se aproximar do que muitas vezes lhe escapa à consciência ou é evitado em função da tensão emocional que evoca (BORIS, 2008).

Enquanto o estudante fala, o supervisor cria um clima favorável através das atitudes facilitadoras para que ele se envolva com o sentido relatado e vá sentindo, experienciado aquilo que foi vivido no momento presente. Assim, o estudante vive a experiência do sentir e vai reconhecendo a importância deste processo ao longo da relação terapêutica (VIEIRA et al., 2018).

\subsection{O serviço de psicologia aplicada}

De acordo com Aires e Kuratani (2017) os Serviços de Psicologia se constituem em espaços obrigatórios de formação, vinculados aos cursos de graduação em Psicologia. Tal obrigatoriedade está prevista nas DCNs a fim de garantir um espaço de formação que integre ensino, pesquisa e extensão com práticas em sintonia com as demandas sociais (BRASIL, 2011). O Serviço de Psicologia Aplicada se caracteriza assim, como um espaço de formação e aproximação entre universidade e comunidade, entre ciência e sociedade, entre a formação técnica e científica e a participação ativa do psicólogo em relação as questões sociais. Ele democratiza a Psicologia, na medida em que se insere dentro de uma realidade social específica, promovendo com isso uma formação profissional realmente pautada nas relações entre teoria e prática.

De acordo com os resultados de um estudo de revisão realizado por Amaral et. al (2012) os Serviços de Psicologia apresentam uma grande variedade de práticas, abordagens e clientelas, o que atesta que estes serviços tendem a se pautar nas demandas especificas da comunidade, cumprindo assim seu papel social de ampliar o acesso da comunidade aos serviços psicológicos de qualidade.

Nos dias atuais, a prática clínica tem se aproximado cada vez mais da realidade social do cliente. Isso significa promover uma concepção de humano no qual interessa tanto 
sua realidade interna, seus significados e sensações quanto sua realidade externa, social, política e cultural. A formação do psicólogo então precisa promover espaços de reflexão contínuos sobre a prática e sua interface com questões sociais que permeiam a realidade do cliente.

Posicionar a Psicologia dentro do contexto social atual, de forma crítica e ativa, implica em desmistificar o papel do psicólogo, especificamente aquele vinculado à herança clínica médica, de atendimento psicológico voltado para o tratamento de problemas individuais, isolados dos determinantes sociais, presentes nas relações interpessoais (WORCIEKOWSKI; PIZZINATO, 2014; GALINDO; TAMMAN, 2020; PIRES; BRAGA, 2009).

Nessa perspectiva, uma Psicologia mais atuante vem se constituindo ao longo dos últimos anos. Isso pode ser observado através do aumento de pesquisas voltadas para a realidade social, de mudanças relacionadas à formação profissional e também de práticas inovadoras que aproximam a Psicologia dos desafios sociais, promovendo ações coletivas e ampliadas para diferentes demandas sociais (WORCIEKOWSKI; PIZZINATO 2014).

A universidade vem se destacando e assumindo um papel importante nesta transformação. Isso tem ocorrido com base em projetos pedagógicos que articulam as Diretrizes Curriculares Nacionais (DCN) com práticas ancoradas em políticas públicas. Essas práticas contemporâneas inserem o psicólogo em ações mais amplas e influenciam na formação de uma identidade profissional mais voltada para as demandas atuais (OLIVEIRA; RIBEIRO; KURATANI 2017).

As instituições formadoras de psicólogos têm sido desafiadas a refletir e rever as práticas para que os profissionais estejam mais preparados para atuarem em campos emergentes, tais como instituições públicas que oferecem serviços para as camadas populares que eram até então privadas do acesso aos serviços psicológicos (GALINDO; TAMMAN; SOUSA, 2020).

\section{A EXPERIÊNCIA DO ESTÁGIO E DA EXTENSÃO NO SPA}

O Serviço de Psicologia Aplicada (SPA) é um órgão ligado ao curso de Psicologia da Universidade Federal de Jataí. Suas atividades tiveram início em agosto de 2010 para atender ao previsto no Projeto Político Pedagógico do curso e se tornar um espaço para as 
práticas formativas da primeira turma que se encontrava no $8^{\circ}$ período letivo (SANTEIRO; ROCHA; ARAÚJO, 2013). Ao longo dos últimos anos, o SPA vem se consolidando como um espaço de diferentes práticas que envolvem ensino, pesquisa e extensão a partir das seguintes ênfases curriculares: Psicologia e Processos Clínicos; Psicologia e Processos Educativos e Psicologia e Processos Psicossociais.

Os estágios específicos do curso de Psicologia, baseados nas três ênfases descritas acima, são divididos em duas disciplinas, oferecidas respectivamente no primeiro e segundo semestres de cada ano, com carga horária de 256h, sendo 64h teóricas e as demais compostas por atividades de leitura, preparação e realização das atividades práticas.

Em 2013 iniciou-se a primeira turma de Estágio Específico Obrigatório em Psicologia e Processos clínicos com enfoque na terapia centrada no cliente. As atividades incluíam, leituras orientadas, supervisão em grupo semanal, elaboração de relatos no formato de versões de sentido, atendimentos psicoterapêuticos para adolescentes e adultos e elaboração de relatório final de estágio como parte dos critérios avaliativos para conclusão do estágio I e II.

Ao longo do tempo, o estágio realizado nas dependências do SPA mostrou ser uma experiência enriquecedora para a formação do psicólogo, tanto do ponto de vista pessoal quanto do ponto de vista teórico-técnico. Além disso, revelou ser um espaço que promovia a reflexão crítica sobre a realidade social dos usuários que buscavam o SPA e os desafios de um curso de Psicologia inserido dentro de uma universidade pública do interior do país.

O espaço de formação que se instituiu levou a um interesse crescente de estudantes pela experiência de formação humanista baseada na terapia centrada no cliente. Ao mesmo tempo, observou-se uma demanda significativamente maior de usuários pelo serviço de atendimento psicológico. Os usuários chegavam ao SPA de forma espontânea ou encaminhados por diferentes instituições que incluíam a própria universidade (principalmente alunos e técnicos), escolas e Unidades básicas de Saúde.

Tendo em vista uma formação integrada com as demandas sociais, em 2016, as estudantes do estágio em processos clínicos receberam a solicitação de ajuda psicológica para além do espaço físico do SPA. A solicitação foi feita por uma diretora de um centro municipal de educação infantil que estava preocupada com a necessidade de apoio psicológico para os professores da instituição. Depois de algumas reuniões, duas estagiárias decidiram propor, 
juntamente com o docente supervisor, uma ação de extensão baseada em uma prática de plantão psicológico para acolher as demandas das professoras ao longo do segundo semestre de 2016. Mais de 70 atendimentos foram realizados neste período. As demandas levadas para o plantão envolveram crises conjugais e problemas relacionais com filhos, conflitos no ambiente de trabalho, problemas de saúde, processo de luto e violência física.

A ação de extensão contribuiu de forma significativa para a redução do sofrimento psíquico e para a solução de problemas relacionais vivenciados pelas educadoras. Ao mesmo tempo, a experiência prática levou as estudantes a reconhecerem a importância de assumirem um protagonismo diante das demandas sociais. Assim, a prática dentro do ambiente escolar mostrou como é possível ampliar o alcance do trabalho do psicólogo envolvendo espaços públicos que anseiam por serviços psicológicos.

Almeida, et al. (2016) ressaltam a importância das ações de extensão como espaço de exercício da prática profissional. Em outras palavras, a extensão permite que o conhecimento teórico possa ser implementado através da prática supervisionada para que o estudante possa desenvolver as habilidades necessárias para a atuação profissional. Com essa perspectiva, a partir de 2017 iniciou-se uma ação de extensão com o objetivo de aumentar o alcance da prática, promover o Atendimento Psicológico e a formação profissional através da Terapia Centrada no Cliente. A ação envolve, desde então, em torno de 15 estudantes de graduação, além de profissionais egressos do curso de Psicologia interessados no exercício da prática clínica supervisionada. Semanalmente todos os estudantes e profissionais se reúnem com o docente responsável pela ação para a supervisão coletiva na qual casos são discutidos a partir de um modelo da terapia centrada no cliente.

As atividades conduzidas nos estágios e na ação de extensão trazem consigo o mesmo modelo de supervisão e prática clínica. No início das atividades, os estudantes recebem orientação específica sobre as normas de funcionamento do SPA, incluindo horários, uso de salas e preenchimento de documentos. Em seguida, os estagiários são preparados em relação aos procedimentos éticos relativos à prática clínica.

Ao mesmo tempo, inicia-se a preparação teórico vivencial que envolve a leitura e a discussão de textos norteadores da terapia centrada no cliente (ROGERS; KINGET, 1977; 1982; 1992; 2008; AMATUZZI, 2019), além de textos clássicos e atuais relacionados aos casos em acompanhamento. Procura-se criar, desde o início, uma relação entre supervisor e 
estudantes em que se valoriza a reflexão sobre as questões sociais atuais que atravessam a formação e a prática do psicólogo, as experiências pessoais, a psicoterapia pessoal e o conhecimento sobre a dinâmica da personalidade.

Além disso, o objetivo deste momento é sensibilizar os estudantes para a estreita relação entre o exercício das atitudes facilitadoras ao longo da supervisão e, por consequência, ao longo da relação terapêutica que o estudante estabelece com o usuário do SPA.

No decorrer da prática supervisionada, verifica-se um processo vivenciado pelos estudantes semelhante às quatro fases descritas por Alves \& Lima (2012): angústia, compreensão, retrocesso e separação. O início da relação terapêutica comumente evoca uma sensação de impotência diante da demanda apresentada pelo usuário. O desejo de ajudar, de demonstrar competência e preparação para um atendimento "eficaz" se depara com obstáculos que emergem tanto da realidade interna quanto externa do cliente e provocam angústia diante da complexidade da relação terapêutica.

A intervenção do supervisor, orientada pelas atitudes de aceitação, autenticidade e compreensão empática se mostram capazes de promover uma relação de crescimento e descobertas. O terapeuta iniciante passa a aceitar o modo de funcionamento singular do usuário como sendo parte fundamental do processo de mudança. Depois de algum tempo de evidente progresso, em muitos casos um aparente retrocesso é explicitado, por exemplo, por atrasos e faltas. O exercício das atitudes facilitadoras durante a supervisão torna-se fundamental para que o estagiário consiga aceitar a realidade do cliente de forma empática. Com isso é possível lidar com os próprios sentimentos, inclusive com aqueles que surgem por conta da separação brusca do usuário em detrimento do fim do semestre letivo.

Durante a preparação teórica, os estudantes são orientados a elaborarem uma versão de sentido (AMATUZZI, 2019), logo após o término de cada sessão. O relato deve incluir aspectos que emergem à consciência, tais como sentimentos e significados experienciados durante a relação. Em seguida o estudante compartilha o relato da experiência com o supervisor, via e-mail. Alguns significados que emergem da versão de sentido são discutidos individualmente com o estudante e outros são levados para serem compartilhados durante a supervisão.

A orientação de encaminhar as versões de sentido para o supervisor foi adotada como uma prática semanal, vinculada ao estágio e à extensão. Essa prática vem se mostrando 
muito enriquecedora no processo de formação, pois, permite que o estudante se sinta acolhido pelo supervisor e possa experienciar sentimentos mais mobilizadores antes de compartilhar e ampliar sua experiência no grupo. Percebe-se com isso que o estudante desenvolve mais confiança e abertura para acessar sentimentos que, até então eram incongruentes com o self atual.

Quando os estudantes começam a se atentar para a influência de seus estados emocionais na relação terapêutica, isso potencializa a expressão das atitudes facilitadoras e, como consequência, amplia as possiblidades de criar um clima mais favorável para a mudança.

Como a terapia centrada no cliente é uma dentre as várias abordagens que contribuem para a formação generalista do estudante de Psicologia, no início das supervisões é comum que alguns estudantes tragam questionamentos e críticas em relação aos conceitos norteadores da prática terapêutica. Estes momentos são utilizados pelo supervisor no sentido de ampliar a reflexão, destacando o potencial e os limites da terapia centrada no cliente. Além disso, estimula-se a busca pelo conhecimento, pela autonomia e a participação ativa na construção da própria formação.

Diante da liberdade de pensar, criticar e refletir sobre a prática terapêutica, os estudantes reconhecem os limites do papel do psicólogo e a importância do trabalho multiprofissional. Reconhecem também o potencial de uma concepção que coloca o ser humano no centro do processo de mudança e acredita que cada pessoa possui os recursos necessários para superar os obstáculos que enfrenta em diferentes momentos da vida. Estes obstáculos incluem não só as relações sociais, mas questões financeiras, valores, discriminação, preconceitos e tantos outros limitadores sociais presentes no cotidiano.

Essa descoberta ocorre ao longo da prática supervisionada e é muito mais experiencial do que teórica. A relação terapêutica vai revelando que boa parte das abordagens psicológicas valoriza atitudes do terapeuta que promovem uma relação autêntica, empática e de aceitação das significações utilizadas pelo cliente para se relacionar consigo mesmo e com a realidade externa. Esta perspectiva é destacada por Bredley (2019) ao afirmar que, ainda com um arcabouço teórico diferente, qualquer abordagem que valoriza as atitudes facilitadoras pode ser considerada centrada no cliente. 
Após a orientação individual que é realizada de forma presencial ou via e-mail, ocorre o encontro semanal com todos os estudantes envolvidos. A supervisão para aqueles que cursam o estágio específico ocorre em dias diferentes da supervisão para os estudantes e profissionais vinculados à ação de extensão, entretanto, o modelo de supervisão adotado é o mesmo.

Inicialmente o supervisor faz uma introdução, destacando aspectos teóricos relevantes em relação às leituras recomendadas e realizadas ao longo de todo o estágio e da prática extensionista. Este momento serve como um aquecimento para que os estudantes se sintam mais à vontade para iniciarem suas narrativas. Nas primeiras supervisões, a presença de colegas muito próximos ou que se conhece pouco promove relatos mais breves e intelectualizados, sem a expressão de significados mais mobilizadores. Como as versões de sentido já foram compartilhadas entre o supervisor e o estudante e os aspectos mais relevantes já foram abordados, o supervisor adota uma atitude de compreensão empática e de aceitação dos sentimentos que emergem no momento da supervisão coletiva. Essa relação genuína é estabelecida com todos os estudantes, procurando sempre que possível, destacar os sentimentos que o estudante vivencia como semelhantes àqueles vividos pelo supervisor e pelo usuário, ressaltando assim que o humano permeia tanto a supervisão quanto a prática terapêutica.

A maior ou menor proximidade com os pressupostos teóricos da terapia centrada no cliente parece influenciar no tempo que o estudante precisa para sentir-se mais seguro em expressar as atitudes facilitadoras. Existe para alguns a impressão de que o fato de "aceitar tudo" o que o cliente trás para a sessão pode promover mais uma imobilidade ou "aceitação passiva" do que uma mudança efetiva na maneira de sentir e lidar com os problemas.

Neste sentido, as leituras previamente definidas sobre os pressupostos e a prática da terapia centrada no cliente são importantes para aproximar os estudantes do conhecimento teórico necessário. As leituras são realizadas ao longo de todo o semestre e utilizadas para subsidiar a prática e a composição da fundamentação teórica do relatório final de estágio ou de atividades. Ao mesmo tempo em que se estimula a leitura, estimula-se também uma atenção maior sobre os próprios estados emocionais a fim de que a sensibilidade oriunda dessa abertura emocional possa contribuir para promover uma relação terapêutica mais atenta e profunda. 
Com o decorrer da prática das atitudes facilitadoras, vai se tornando mais claro a presença de uma tendência atualizante em cada usuário do serviço de Psicologia. $\mathrm{O}$ estudante começa a reconhecer mais facilmente que existe um potencial presente e suficientemente capaz de promover a superação dos problemas e obstáculos atuais. Essa descoberta ocorre mais ou menos ao mesmo tempo em que se experiencia esta tendência em si mesmo, diante da superação de medos e incertezas decorrentes do processo de formação profissional e das relações pessoais (ROGERS, 1992).

Neste momento do processo de supervisão, os estudantes tornam-se mais conscientes de suas características pessoais, muitas antes pouco percebidas. Passa a se atentar mais para padrões comportamentais que colaboram e outros que impedem mudanças efetivas na maneira de lidar com sua realidade pessoal e profissional. Tal discernimento parece oferecer uma ampliação na maneira de entender a si mesmo dentro de um contexto social tão diverso e complexo. É como uma descoberta de uma liberdade experiencial que até então não era permitida ou aceita. Essa vivência também contribui para promover uma compreensão mais ampla do papel do psicólogo na sociedade, um papel crítico e de promoção da saúde e da valorização da liberdade do pensamento (SCHMIDT, 2011).

A compreensão dos efeitos das atitudes facilitadoras sobre as relações humanas, para além da que são experienciadas no processo terapêutico surge mais ou menos no mesmo período de encerramento da prática supervisionada. As últimas supervisões são permeadas por relatos que descrevem o processo de mudança dos estudantes e dos usuários do serviço. A expressão autêntica da maneira como sente e uma compreensão empática em relação aos colegas torna-se mais comum entre os estudantes. A aceitação positiva do próprio self é expressa muitas vezes com uma disponibilidade maior para buscar outras formas de vivenciar as relações e enfrentar os problemas que surgem ao longo da formação profissional.

Os relatórios finais de estágio e de extensão documentam este processo de mudança e de formação do estudante de Psicologia. São expressões do conhecimento teórico adquirido, das reflexões sobre a realidade social, da prática clínica e da formação humana do psicólogo. 


\subsection{Desafios para a formação profissional no serviço de psicologia aplicada}

De acordo com um estudo realizado por Oliveira et. al. (2014), um aspecto importante para o processo de supervisão nos serviços escola de Psicologia se refere à avaliação do processo. Os resultados do estudo atestam a valorização da supervisão tanto pelos supervisores quanto pelos estagiários. Alguns fatores destacados como importantes durante a supervisão envolvem a empatia, o aprimoramento do aprendizado e a compreensão. Todos os fatores parecem reconhecer que as atitudes do supervisor ao longo da supervisão são essenciais ao processo de formação profissional.

Nesta perspectiva, um primeiro desafio para a formação profissional no SPA se refere à construção coletiva de formas de registro e de avaliação das práticas desenvolvidas. $\mathrm{O}$ fato de as práticas serem conduzidas por docentes diferentes e com abordagens diferentes parece dificultar ações integrativas que poderiam ser elaboradas, registradas e avaliadas coletivamente.

Um outro desafio atual é relacionar ações de ensino, pesquisa e extensão fomentando uma formação mais integrada, conectando diferentes abordagens teóricas com uma participação ativa em relação às demandas sociais, ressaltando o papel do psicólogo em práticas formativas e transformadoras.

Dentre os desafios institucionais destaca-se a necessidade de reconhecimento da importância do SPA pela própria universidade, o que poderá mudar com investimentos como a construção de um espaço físico adequado para atender as necessidades de acesso de usuários e estudantes.

Os serviços oferecidos no SPA atendem dois públicos: a comunidade interna (os estudantes) e a comunidade externa (a população do entorno), cada um desses possuindo demandadas especificas de cunho individual e social, que podem contar apenas com o serviço gratuito que a universidade oferece. Nesse sentido, um outro desafio é atender toda a demanda, considerando que praticamente todos os serviços são realizados por estudantes. Dito de outra maneira, existe uma grande demanda atual e um número reduzido de estudantes em condições de oferecer os serviços. Neste sentido, Amaral et al., (2012) apontam que nas Clínicas Escolas de universidades o desafio se articula entre a necessidades da formação acadêmica e as necessidades sociais, sendo de suma importância que o estudante tenha uma 
formação que garanta subsídios e conhecimentos necessários para que consiga lidar com tais demandas.

Por fim, Barletta e Fonseca (2012) ressaltam que o ambiente da supervisão é reconhecido pelos estagiários como sendo fundamental para promover o exercício das atitudes facilitadoras e contribuir com o crescimento pessoal e formação do psicólogo. Entretanto, Silva (2006) aponta que um desafio para a formação profissional baseada na abordagem centrada na pessoa é exatamente manter um ambiente favorável para o exercício dessas atitudes, tanto para o supervisor quanto para o estudante. Entende-se assim que a prática supervisionada se constitui em um processo em constante movimento, desafiando docentes e estudantes a estarem em constante exercício teórico e experiencial.

\section{CONSIDERAÇÕES FINAIS}

Ao final das considerações apresentadas neste texto, conclui-se que a formação clínica do psicólogo a partir do referencial da terapia centrada no cliente oferece subsídios importantes para uma prática que reconhece no humano o potencial para a mudança em si e nas relações que estabelece com a realidade social e seus influenciadores.

Entretanto, a prática terapêutica só se torna capaz de potencializar a mudança no cliente na medida em que as atitudes facilitadoras são experienciadas pelo próprio estudante. Essas experiências tendem a promover um jeito de ser que valoriza de forma genuína a aceitação positiva, a compreensão empática e a autenticidade nas relações com o cliente, com os colegas de supervisão e com o supervisor. Neste sentido, os estágios e as ações de extensão se mostram como espaços importantes para o exercício das atitudes facilitadoras e da terapia centrada no cliente.

A supervisão se constitui como parte essencial da formação, favorecendo a aproximação entre o conhecimento teórico e técnico e a prática das atitudes facilitadoras. Além disso, é um momento potencializador do debate, da crítica e de um posicionamento ativo e autônomo dos estudantes em relação à formação e atuação do psicólogo na comunidade.

Neste sentido, conclui-se que as práticas de formação profissional desenvolvidas no SPA colaboram de forma efetiva para democratizar os serviços psicológicos, gerar conhecimento e ampliar a participação do psicólogo na comunidade. 


\section{REFERÊNCIAS}

AIRES, S.; KURATANI, S. Apresentação. In: .(Orgs). O Serviço de Psicologia na Universidade. Cruz das Almas: Editora da UFRB, 2017. p. 07-14.

ALMEIDA, M. C. D. S. et al. A formação do psicólogo clínico: considerações a partir de um projeto de extensão com famílias. Revista Sul Americana de Psicologia, v. 04, n. 02, p. 273 $297,2016$.

ALVES, V. L. P..; DANTAS, D. L.. Os primeiros passos no processo de tornar-se psicoterapeuta sob o referencial da Abordagem Centrada na Pessoa. Revista Brasileira de Psicoterapia, v. 14, n. 01, p. 58-70, 2012.

AMARAL, A. E. V. et al. Serviços de psicologia em clínicas-escola: revisão de literatura. Boletim de Psicologia, v. 62, n. 136, p. 37-52, 2012.

AMATUZZI, M. M.. Versão de sentido. In: Por uma psicologia humana. Campinas: Alínea, 2019. p. 85-101.

BARLETTA, J. B..; FONSÊCA, A. L. B.. Avaliação do processo supervisionado como norteador de ensino de psicoterapia: reflexões sobre a vivência prática. Revista de Psicologia da IMED, v. 04, n. 01, p. 671-680, 2012.

BRASIL. Ministério da Educação. Conselho Nacional de Educação. Câmara de Educação Superior (2011). Resolução n5, de 15 de março de 2011. Institui as Diretrizes Curriculares Nacionais para os cursos de graduação em Psicologia, estabelecendo normas para o projeto pedagógico complementar para a Formação de Professores de Psicologia. Diário Oficial da União, Brasília, DF, p. 01-08, março. 2011.

BRODLEY, B. T.. Client-Centered Therapy - What Is It? What Is It Not? The Person Centered Journal, v. 24, n. 1-2, p. 37-59, 2019.

BORIS, G. D. J. B. Versões de sentido: um instrumento fenomenológico-existencial para a supervisão de psicoterapeutas iniciantes. Psicologia Clínica, v. 20, n. 01, p. 165-180, 2008.

BUYS, R. C. Supervisão de psicoterapia na Abordagem centrada na Pessoa. São Paulo: Summus, 1987.

FREIRE, E. S.; TAMBARA, N. Person-centered therapy: client-centered terapy: the challenges of clinical practice. The Person Centered Journal. V. 7, n. 2, p. 129-138, 2000.

GALINDO, W. C. M.; TAMMAN, B. F.; SOUSA, T. B. S. Estratégias formativas em serviços-escola de Psicologia. Psicologia: Ciência e Profissão, v. 40, e188175, p. 1-15, 2020. 
KIRSCHENBAUM, H.; JOURDAN, A.. The current status of carl rogers and the personcentered approach. Psychotherapy: Theory, Research, Practice, Training, v. 42, n. 01, p. 37-51, 2005.

MONTEIRO, N. R. O; NUNES, M. L. T.. Supervisor de psicologia clínica: um professor idealizado? Psico-USF, v. 13, n. 2, p. 287-296, 2008.

OLIVEIRA, F. L. B.; RIBEIRO, L. M..; KURATANI, S.. Serviços de psicologia: para quê e para quem? In: AIRES, S..; KURATANI, S.. (Orgs). O Serviço de Psicologia na Universidade. Cruz das Almas: Editora da UFRB, 2017. p. 15-26.

OLIVEIRA, M. S. et al. Supervisão em Serviços-Escola de Psicologia no Brasil: Perspectivas dos Supervisores e Estagiários. Psico, v. 45, n. 2, p. 01-09, 2014.

PATTERSON, C. H.. Client-centred Supervision. In:___. Understanding Psychotherapy: Fifty Years of Client-Centered Theory and Practice. Monmouth: PCCS Books, 2000. p. 134-146.

PIRES, A. C. T.; BRAGA, T. M. S.. O psicólogo na saúde pública: formação e inserção profissional. Temas em Psicologia, v. 17, n. 01, p. 151-162, 2009.

ROGERS, C.. As condições necessárias e suficientes para a mudança terapêutica de personalidade. In: J. Wood et al. (Orgs.). Abordagem centrada na pessoa. Vitória, ES: EDUFES, 2008. p. 143-161. (Original publicado em 1957).

ROGERS, C.. Terapia centrada no cliente. Tradução de Cecília Camargo Bartalotti. São Paulo: Martins Fontes, 1992. (Original publicado em 1951).

ROGERS, C.; KINGET, M.. Psicoterapia e relações humanas: teoria e prática da terapia não-diretiva. Belo Horizonte: Interlivros, 1977. (Original publicado em 1962).

ROGERS, C. Um jeito de ser. São Paulo: EPU, 1983 (Original publicado em 1980).

SANTEIRO, T. V.; ROCHA, G. M. A.; ARAÚJO, D. S. A. Implantação de um serviço-escola de psicologia no centro-oeste brasileiro: usuários e atendimentos. Perspectivas em Psicologia, v. 17, n. 02, p. 65-82, 2013.

SCHMIDT, M. L. S.. Utopia, Teoria e Ação: Leitura das Propostas Grupais na Abordagem Centrada na Pessoa. Psicologia: ciência e profissão, v. 31, n. 03, p. 628-639, 2011.

SHARF, R. S. Person-centered therapy. In: Theories of psychotherapy and counseling: concepts and cases (5th ed). Belmont: Brooks/cole, 2012. p. 206-239.

SILVA, N. O.; AMARAL, S. R.; RODRIGUES, M L. F. M.. Formação de psicólogos clínicos a partir da Abordagem Centrada na Pessoa. Revista Científica e Tecnológica, v. 04, n. esp., p. 135-156, 2018. 
SILVA, R. B.. A função da supervisão na formação do psicólogo clínico na abordagem centrada na pessoa. 2006. Dissertação de mestrado (Programa De Pós-Graduação Em Psicologia), Pontifícia Universidade Católica Do Rio Grande Do Sul, Porto Alegre.

TALLEY, L.; JONES, L. Person-Centered Supervision: A Realistic Approach to Practice Within Counselor Education. Teaching and Supervision in Counseling, v. 01, n. 02, p. 2030, 2019.

TAVORA, M. T. Um modelo de supervisão clínica na formação do estudante de psicologia: a experiência da UFC. Psicologia em Estudo, v. 7, n.1, 121-130, 2002.

VIEIRA, E. M.; BEZERRA, E. N.; PINHEIRO, F. P. H. A.; CASTELO BRANCO, P. C.. Versão de Sentido na Supervisão Clínica Centrada na Pessoa: Alteridade, Presença e Relação Terapêutica. Revista Psicologia e Saúde, v. 10, n. 01, p. 63-76, 2018.

WORCIEKOWSKI, C. F.; PIZZINATO, A. Estágios Básicos: como as práticas profissionais e as Diretrizes Curriculares Nacionais repercutem na formação e atuação do psicólogo. Psicologia e Argumento, v. 32, n. 79, p. 45-56, 2014. 